\title{
An Introduction of Reflective Teaching Styles for Oral Surgery
}

\author{
${ }^{1}$ Amaar Hassan, ${ }^{1}$ Asfa Mughal, ${ }^{2}$ Matthew Morris, ${ }^{3}$ Tariq Ali \\ ${ }^{1}$ Edge Hill University, $U K$ \\ ${ }^{2} U C L A N, U K$ \\ ${ }^{3}$ University of Queensland, Australia
}

\begin{abstract}
There is limited research on the teaching of removal of impacted wisdom teeth at an undergraduate and postgraduate level with pig models. The sessions presented in this assignment offer a commentary and reflection into the different styles of teachings for the surgical extraction of teeth using presentations, case-based learning and simulation. This article is split into three sessions; the first consisted of theory and practical, enabling students to enhance their existing knowledge of Oral Surgery. The second session involved the extraction of teeth using simulation, enabling students to increase their exposure through differing clinical situations. The final teaching session was a one-toone encounter, for a surgical extraction, on a real patient. The focus of the session was to remain as a mentor, rather than a teacher. The learning objectives, style of teaching and feedback are all considered when determining the effectiveness of the teaching sessions and may support a diverse group of learners. However, it is also important to deliver individual needs for students to satisfy every student towards their own learning objectives.
\end{abstract}

\section{Introduction}

Simulated learning is a useful method in this situation, due to students limited experiences when learning in clinical situations [1]. Indeed, Ali et al [2] offers some insight into the variable teaching of wisdom teeth extraction at undergraduate level and that this may be due to the General Dental Council [3] offering little guidance on teachings for wisdom teeth removal and how much exposure a clinician requires for graduation.

The first session consists of a student-focused discussion with eleven Dental Core Trainees (DCTs) with similar clinical experience to participate at the study day. The students identified wisdom teeth extractions as a developmental need prior to the session and therefore already highlighted as a useful topic. Learning objectives and outcomes were sent in an email to the students prior to the study day (Figure 1). The morning consisted of mainly an interactive "theoretical" session, enabling the students to grasp their existing knowledge of oral surgery scenarios, whilst encouraging their own learning outcomes and further reading. This was achieved using brainstorming, presentations and lectures prepared by the students before and during the session. There were also some practical elements to the morning designed to keep the students focused and adding some teaching variety.

\begin{tabular}{|c|c|c|c|}
\hline Time & Title & Presenter & Equipment required \\
\hline 9.10 & Introduction & $\mathrm{AH}$ & Flip chart \\
\hline 9.25 & $\begin{array}{l}\text { Principles of excisional } \\
\text { biopsy }\end{array}$ & SS/LT & \\
\hline 9.40 & $\begin{array}{l}\text { Principles of incisional } \\
\text { biopsy }\end{array}$ & SM/MB & \\
\hline 9.55 & $\begin{array}{l}\text { Haemostasis } \\
\text { (including monopolar, } \\
\text { bipolar, silver nitrate) }\end{array}$ & NA/IA & $\begin{array}{l}\text { Monopolar } \\
\text { bipolar (tips available?) }\end{array}$ \\
\hline 10.1 & cryosurgery & $\mathrm{AK} / \mathrm{BO}$ & Cryotherapy machine \\
\hline 10.40 & \multicolumn{3}{|c|}{ Break } \\
\hline 10.55 & $\begin{array}{l}\text { Sutures (types and } \\
\text { techniques) }\end{array}$ & $\mathrm{CM} / \mathrm{TN}$ & \\
\hline 11.10 & Surgical hand ties & $\mathrm{AH}$ & rope \\
\hline 11.25 & \begin{tabular}{|l} 
soft tissue surgery \\
- incisional biopsy for \\
diagnosis \\
- excisional biopsy - \\
FEP, pyogenic \\
granuloma, mucocele, \\
calculi \\
- suturing practice
\end{tabular} & AH/STC & \begin{tabular}{|l|} 
(Pictures of lesions) \\
Bipolar, \\
cryotherapy machine \\
drapes + metal trays \\
disposable suture packs \\
suture types \\
pigs skin \\
binbags \\
\end{tabular} \\
\hline 1.00 & \multicolumn{3}{|c|}{ Lunch } \\
\hline 2.00 & $\begin{array}{c}\text { Radiographic } \\
\text { interpretation for 8's }\end{array}$ & $\mathrm{MD} / \mathrm{JT}$ & \\
\hline 2.15 & $\begin{array}{l}\text { Use of cone beam and } \\
\text { its implications } \\
\text { (consent, tx options - } \\
\text { operculectomy, } \\
\text { coronectomy) }\end{array}$ & $\mathrm{AH}$ & \\
\hline 2.30 & $\begin{array}{c}\text { Basic SR principles } \\
\text { (LA, flap design, bone } \\
\text { removal, sectioning, } \\
\text { closure) } \\
\end{array}$ & AH (with STC) & \\
\hline 3.00 & \multicolumn{3}{|c|}{ break } \\
\hline 3.15 & $\begin{array}{c}\text { Simulation of surgical } \\
\text { extractions. }\end{array}$ & AH/STC & $\begin{array}{c}\text { Drapes + metal trays } \\
\text { pigs heads (6) } \\
\text { scalpel } \\
\text { surgical kit } \\
\text { drill }\end{array}$ \\
\hline
\end{tabular}

Figure 1. Learning Objectives for the session/lesson plan

The second session enabled the students to split into groups of two for an afternoon session, with myself and two other clinicians supervising them. The learning objectives of this session were designed so that the students could utilise the knowledge gained from the morning session and apply this when extracting the teeth on the pig model. Simulated learning is a useful method in this situation, due to student's limited experiences when learning in clinical situations [1]. In this session, I wanted to demonstrate that knowledge is not just the ability of 
technical skill, but of the process of applying theory and technique from scientific knowledge.

The final session involved a one-to-one clinical encounter with surgical removal of a wisdom tooth under local anaesthetic on a patient. The student may apply their knowledge gained from previous teachings into a real scenario. It also covers the techniques used in a clinical setting, and how these sessions can be adapted to support diverse learners, whilst maintaining student-focused learning. During this session, I had maintained my position as a mentor, rather than a teacher, to create a positive atmosphere in the clinical setting.

\section{Minor Oral Surgery Techniques (Theory)}

The study day was structured into four parts; two in the morning and two in the afternoon. The first three parts were mainly theoretical discussions, the first three parts of the session are discussed, which were mainly theoretical, but they also involved some case-based scenarios (with radiographs), simulation and clinical activity. This was so that I could provide the learners with some variation in learning styles, throughout the morning and afternoon. The last part of the session was with procine model and is discussed more in session two.

The audience were all graduates of dentistry, working as DCTs in the Maxillofacial department at Hull Royal Infirmary. Although this was a compulsory teaching session, these types of learners will certainly be involved in teaching and continued development at some point in their professional careers. I wanted to create an atmosphere that introduced key principles of oral surgery, whilst also engaging the student's deeper thinking skills and facilitating effective group learning. I knew this topic would be a relevant one, as on a previous study day, the students had asked for a session on oral surgery, as they felt like they were not getting enough experience. It was also useful to note that all the DCTs had a similar background of clinical experience, so that the topic was not overly exhausting or too simplistic for the students.

The cohort involved eleven students. This is considered as rather large by some scholars; groups larger than eight individuals means that contributions from students may start to decline [4]. McCorie in 2006 advised that having groups larger than eight enables some students to avoid participating, however this situation was difficult to rectify as I was not able to choose the group size [5]. Broadly speaking, smaller groups may increase positive learning and thinking, however, much of this research lacks validity [6]. It is important that the effectiveness of teaching does not solely focus on group size. McCorie [5] also discusses that there are multiple factors, which may influence effective learner experience, such as a positive atmosphere, critical thinking and involving students more in active learning. I felt like in my session, students would still participate effectively as they were all encouraged to presentation and brainstorming exercises, and this approach would maintain the usefulness of small group techniques in this 'larger' group.

The lesson plan I had created was also sent to the learners a couple of weeks before the session, highlighting background knowledge needed, general aims and objectives for the day. There were a few reasons why I emailed this prior to the lesson. These were so that the aims and objectives of the session were clear, and that meant the outline for the day created a safe environment; they would be able to prepare appropriately for their own lectures and nothing would be unexpected. From my own experience, I found lecturers often publish further reading at the end to encourage students for further reading, however releasing material before the session enables students to participate and make comments in the class by using the resources provided. There is increasing evidence for using online resources, which may enhance the student's ability to learn outside the classroom [7]. Despite this, it is still important not to detract the students from making the session as interactive as possible, as the available literature suggests that learners still prefer classroom activities over learning online [7].

The first part of the morning session had the students in pairs performing presentations on allocated topics. These involved the students giving lectures on simple surgery, such as biopsies and using haemostatic agents. The students were split up into pairs and assigned a task; to discuss all the principles of minor oral surgery using presentations they had prepared prior to the session. The idea was to work together which would accomplish the learning objectives for the study day. The use of cooperative learning during group activities is well known; Johnson et al evaluated the uses of cooperative learning in groups and how this can be used to facilitate learning and promote positive relationships amongst colleagues [8]. The students were assigned a topic and they were encouraged to participate in small ten-minute presentations, with a teaching style of their choice. There were some difficulties with the presentations lasting only ten minutes long. The learners had a lot to cover, so the session ran longer than expected. It also meant that some of the students rushed their presentations, as they were aware of the time constraints. One example of this was a student's presentation of excisional biopsies (cutting off skin lesions). The student presented a lecture, and then at the end, provided each participant with a clinical case. A sheet of paper with a lesion drawn on a lower lip was provided, and the students had to draw out a design 
for the excision. However, as there was not much time left, it was rushed, and he pursued to give the answer before anybody had a chance to draw anything. As a result, one student wrote on the feedback form for his presentation (Figure 2) that he should have spent more time allowing the students to proceed with the interactive element of his session. This is something that I reflected on also, as it is difficult to expect students to present on topics for ten minutes, which are perhaps exhaustive.

The role as a facilitator, rather than a teacher, switches a traditional didactic approach into a structured session. Open-ended questions were used with the rest of the learners, rather than picking on specific people, such as 'how did you find that presentation?' These questions were used if I felt the topic digressed or that there were still some objectives to go through. At the end of the session I encouraged reflective thinking for the students by providing everyone with forms to complete anonymous feedback (see Figure 2).

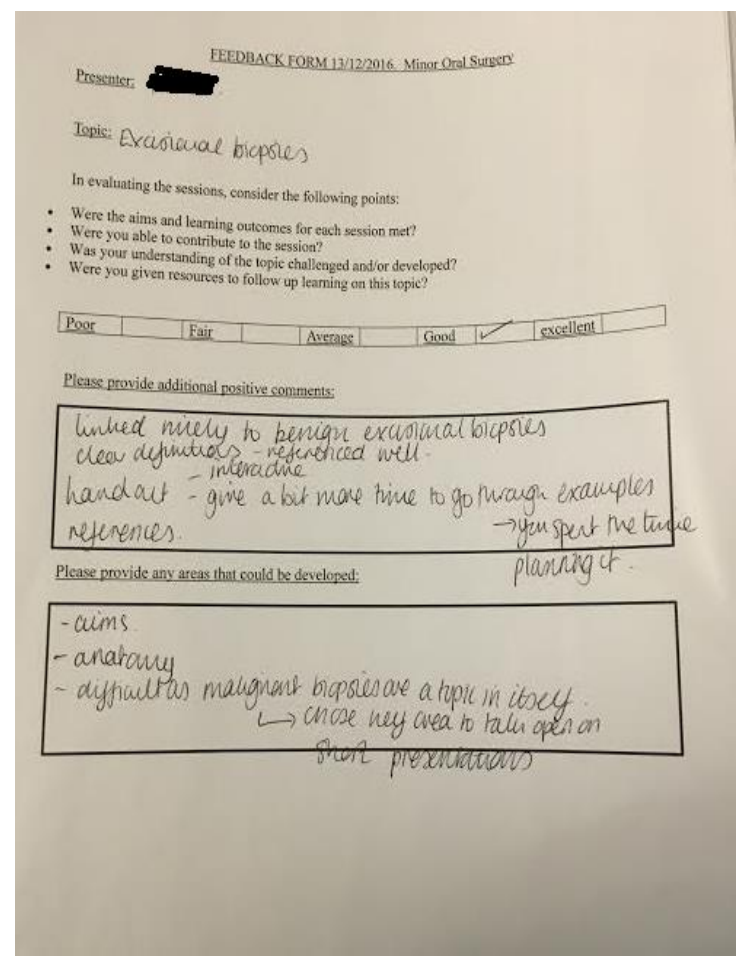

Figure 2. Anonymous feedback form

The second session of the morning, after the break, continued with presentations from the students in pairs. I had brought some props to help the students engage in learning, and to develop clinical skills which would go hand in hand with the theoretical aspect. Kolb's experiential learning cycle (1984) discussed a cyclical approach to learning, which is enhanced by practising and gaining as much clinical experience as possible [9]. Therefore, the students suturing on the models and tying surgical knots would develop their own skills. I was aware that the students already had reasonable exposure to suturing. Therefore, they did not require extra facilitators to accommodate for small teacher-learner ratios. I did not provide much feedback, as this was a chance to get some practice and have a break from lectures, rather than develop new skills.

At the start of the third session, the students were divided into groups to brainstorm a scenario based on wisdom teeth radiographs, which I had provided. They would then allocate a speaker to summarise their ideas to the rest of the students. Race has analysed that learners are more active by discussing case scenarios with peers and finding solutions [10]. This way of learning is more efficient by stimulating the student's interest and curiosity to learning and is a preferred approach to didactic learning. There are also few opportunities with traditional lectures for students engaging in feedback; however, the possibilities are much more significant during brainstorming sessions, with other students asking questions to gather a response.

The style of learning in the session is largely based around Lave and Wenger [11] and is a critical component to learning by students due to being more active in the session. The social interaction, with students being involved in the 'community' encourages social interactions and constructivist theories to learning built upon by Vygotsky [12].

I am aware that many of the individuals had little experience in teaching, yet teaching may become an integral part of their careers. Having developed my own skills using postgraduate education, I have been able to reflect on my own approaches and use this to develop my teaching experiences and encourage a positive atmosphere of learning. It was important for me to engage others in student focused teaching, so that they may enhance their own learning skills and provide a positive environment for learning in the future, with a double-loop style of learning [13]. Double-loop learning encourages teachers to think more about their own beliefs and objectives, with the idea of becoming better leaders. Therefore, training fellow students to become better teachers by selfreflecting more may encourage them to build up their own leadership skills as well as experience learning.

Although the session was largely successful, I felt like there were some limitations to group sessions. Students resistance to Problem-Based Learning (PBL) sessions can cause them to be slightly disjointed for the first few sessions, however this usually resolves once the students have participated in more PBL sessions [14]. In this session, the presentation involving Computed Tomography (CT) scans became largely disjointed, as the student who was delegated the task of this topic was absent on the day, therefore I had to read out the student's lecture as a last-minute decision. I felt as though I had not prepared the presentation, therefore I had not gained the knowledge to present 
this lecture appropriately. Also, I was aware that I was not vastly more experienced or senior than others in this topic, therefore I asked one of the maxillofacial consultants to attend and oversee the session as a senior figure and second facilitator, which was useful to use him as a point of reference if the group became stuck with grasping concepts such as this one. Despite this, the overall feedback was very good, with all the students mentioning that they had learnt a lot. I feel like this was mainly due to making sure that the individual's collective developmental needs were met. The students were given an opportunity to identify their learning needs. During the morning session, the students were asked to name one thing that they would like to cover during the day, with all the points raised written on a viewing board. After the mid-morning break I asked students to write on a sticky note one thing they had learned so far, and at the end of the session I set aside fifteen minutes to discuss learning outcomes, what we had learnt in the day, and whether they felt like this had been achieved. This also gave me an opportunity to look back at the developmental needs highlighted by the students written on the board and to check we had covered all the points.

\section{Minor Oral Surgery (simulation and reflection)}

As Kolb [9] famously described the cyclical nature of experiential learning is a continuous motion through observing, reflecting and experiencing. Kolb [9] argues that when there is more purposeful learning, objectives and planned activity, clinical experience will help facilitate learning. Thus, performing surgical extractions on procine models appear promote experiential learning, as this session encouraged a more hands approach as opposed to theoretical knowledge only. There is limited research on the teaching of surgical removal of impacted wisdom teeth at undergraduate and postgraduate level with pig models. A systematic review [15] recognised that simulation is a recognised tool when there is feedback provided in the educational experience, although its data presented was equivocal, rather than statistical. Zangrado et al. [16]. evaluated feedback using pig mandible for certain oral surgery techniques and concluded that these sessions offered advantages due to its similarities to tissues with humans, providing a high level of education. Despite this, the techniques offered in the study were not of wisdom teeth, but were other techniques used in periodontal surgery. The same teaching principles may be applied to a session involving surgical removal of wisdom teeth however.

The afternoon session involved a simulation of surgical extractions with pigs heads, and the students were split into groups of two. A quick debrief of the session was outlined to the students. The procedure involved picking a suitable tooth, raising a flap with a blade, drilling jaw bone and then elevating the tooth out using instruments. There were only two bone drills in the session, so the students had to rotate the drill between, however this was still sufficient for the session. Between the 11 students, there were three clinicians (including myself) who volunteered to act as facilitators, so that there were an increased number of teacher to learner's ratio, which would maximise feedback and learning output.

As the students in this session were all dentists who have begun a career with the need for continued professional development, it was important for me to develop self-reflection skills, which would help the students learn from their own experiences. To help the students become more reflective, I would attempt to ask the right questions, rather than give answers. This would be useful to the learners to develop independent reflective skills [17]. For example, why did you feel you were not able to take the tooth out? What do you feel went well, and what did not?

This session was one that I hoped would be an open, safe environment for clinical learning without patients, which would encourage an open and honest area for self-reflection and feedback. Students were engaged to a session that would focus on attention, reflection and compassion rather than focusing on outcomes, clinical competence, and efficiency [18].

Although the trainees were roughly the same level, there was one student whom at the start had told me she had rather limited experience on surgical extractions, and that she had little confidence in her own technique. It seemed apparent that most of the other students had a few more years of exposure to surgical extractions, which may have been the reason why she appeared to approach me at the start. She had recently graduated from Dentistry at Birmingham and had only been practising for 6 months. She went on to discuss that during her experience at undergraduate level she did not gain much exposure of wisdom teeth extraction. This may be due to the General Dental Council [19] offering little guidance on teachings for wisdom teeth removal and how much exposure a clinician requires for graduation.

An explanation was given on how the simulation session would benefit her, as this was an opportunity for her apply all her theoretical knowledge to the clinical encounter. This session would give her exposure to the skills needed for oral surgery, and that we were separate from the pressures in a clinical environment. This was an opportunity for her to reflect on and address developmental needs in a safe environment that would improve her skills on her pathway to learning. With this student, I felt like she required some confidence building and was in need for one-to-one tuition. A review by Luhanga [20], describes one-to-one tuition as an important tool in 
developing a safe and effective beginner. I decided with this student, I would first attempt a surgical removal of a tooth whilst she observed, so that she would gain more exposure observing a clinical procedure. Whilst performing the surgical removal of the tooth, I was speaking aloud and reflecting, so that she understood my approach during the clinical encounter. This approach is a concept designed for students to capture thought processes and can be used to assess competence in the clinical setting. During one-to-one tuitions, there can be limited discussions during the procedure, as the facilitator does not usually explain his or her methods. This restricts the learner's ability to reflect and analyse methods used in the session to apply for future cases. Therefore, clinical reasoning is an important factor in reducing errors in the medical profession, despite advances in technology and protocols.

The student was delighted with most of the tuition I was able to offer with her observing incision of the gum, bone removal and some tooth elevation. However, I realised the other students were also seeking feedback, therefore I was not able to complete the full procedure. There were eleven students to three clinicians to oversee the clinical encounter. This meant that there was a closer interaction with students due to a small student to teacher ratio. However, it did become difficult to discuss personal feedback throughout the whole procedure of the other students, I was only able to visualise some aspects of the procedures, and ask the students how they felt it went, rather than directly observing the whole session with one student. Oneto-one tuition would have been more personal and provided detailed and immediate feedback to students [18].

It was obvious during the session that different students had various preferences for learning and some required more attention than others. I was careful, like with the individual student mentioned earlier, to adapt to personalities to maximise learning in that clinical environment. However, I made sure I was not too adaptable as I wanted to encourage independent learners who could adapt to different situations.

\section{Minor Oral surgery, One-to-one, in a Clinical setting}

The final session involved a patient who required Multiple dental extractions under local anaesthetic. The team involved myself, two dental nurses and an LDFT1 (Longitudinal Dentist Foundation Training) who was the learner. An LDFT1 is a dentist in their first year (of two years) training after graduation. They are competent to treat patients but are often supervised. They train one week in general dental practice and one week in hospital setting. My role at the department is a dental core trainee (DCT), which involves generalist training, surgical, teaching skills and is equivalent to an LDFT2.

Fugill evaluated that dental students responded positively when the teacher had desirable characteristics, such as knowledge, professionalism and respect [20]. I am only one year ahead of the student regarding training, and I was aware that my knowledge of the procedure may not have been much more than the student. Therefore, I was particularly careful to implement some other aspects of positivity in teaching described by Fugill such as feedback and student autonomy. Despite being a senior by only one year, I felt that it was an advantage, particularly during a one-to-one situation [20]. By dressing appropriately, arriving promptly, maintaining professionalism you can model desirable attributes for the student to aspire to over the next years and act as a mentor, whilst still providing clinical apprenticeship [21]. You can still develop close relationships with students of a similar age and status. Dental students value these types of relationships with a learner, as they can offer regular contact at the department, comfort, and clinical support. A consultant, may not have the same clinical timetable or be around the student's computer room during lunch hours to build relationships with learners as they often have other responsibilities. Despite this, I was still aware of my own limitations, as my role as a DCT has rather limited experiences to teaching. I asked a consultant if he would oversee the session and provide a second role as a facilitator should we both become unstuck with the clinical procedure. I felt like having the consultant nearby would provide the student with reassurance during the session in case there were any complications.

My aims of the session were to assist the student with independent clinical reasoning, learning and reflection, whilst applying the teaching styles already discussed in the previous sessions. Most of all, I wanted to act as a mentor to the student. A mentor is a teacher who takes a unique interest in the student's career, providing support and guidance.

Before the procedure, the learner and I spoke about the patient, medical history and clinical procedure. We identified potential complications, and I did this by asking open ended questions, such as, "which teeth do you would think may pose a problem and why?" I then asked how she would perform a local anaesthetic to the patient, and the student answered appropriately. I posed a different question to the student, prompting cognitive skills. I asked if I was a patient that needed both upper wisdom teeth out and had a gag reflex, how would you perform a local anaesthesia differently. The student was unsure of this answer and I encouraged the student to read up on the anatomy of the palate and get back to me, the answer to this question was 
not relevant to the patient but I still wanted to promote active learning and reflection.

I felt it was important to set some ground rules, as it was still patient interaction; this was to reduce stress levels and the occurrence of any unexpected events. For example, the notes highlighted that the patient was nervous, therefore we agreed not to discuss anything that would make the patient more anxious. If the student was struggling, then I would try to avoid taking over and offer support and guidance, as a role of a mentor.

Once the patient arrived, I assumed this background role, an assistant, a facilitator, whilst the student led the clinical procedure. I spoke very little and took the role of a dental assistant during the procedure. Whilst the student was performing one of the extractions, the root snapped, however she was still able to retrieve the piece without my assistance or guidance. Once the patient had left I gave the student feedback. I did not feel it would be appropriate to provide this during the clinical procedure (as the patient was nervous), however it was still important to direct the leaner to think about her own performance during a one-to-one session. I advised the student that often when I had extracted teeth, the patient 'jumped' up in the chair a little bit when I held the tooth with forceps. When she was performing her extractions, the patient was not doing this, and I suggested that if she applied more apical pressure, then the tooth would be less prone to breakage. Generally, the student was very good, and I did not want to provide an exhaustive list of detailed feedback and demotivate the student.

In summary, the student was confident, and the procedure was not complicated, therefore this helped me in my role as a mentor for this session, and the student as an independent learner. A future one-toone tuition could involve a more complex tooth extraction. I feel like a more challenging clinical procedure would have also provided the student with more comprehensive feedback of the session.

\section{Conclusions}

Performing surgical extractions on pigs appear to promote experiential learning, as this session encouraged a more hands approach, as opposed to theoretical knowledge only. There is limited research on the teaching of surgical removal of impacted wisdom teeth at an undergraduate and postgraduate level with pig models. A systematic review recognised that simulation is an important tool when there is feedback provided in the educational experience [15], although the data presented was equivocal, rather than statistical. Zangrado et al [16] evaluated feedback using pig mandible for certain oral surgery techniques and concluded that these sessions offered advantages due to its similarities to tissues with humans, providing a high level of education. Despite this, the techniques offered in the study were not of wisdom teeth, but involved other techniques used in periodontal surgery. However, the same teaching principles may be applied to a session involving surgical removal of wisdom teeth.

I wanted to create an open and dynamic relationship with the students that provided a safe environment. I would accomplish this by changing my role to a facilitator, rather than a teacher. I decided to sit quietly and listen to the students during the teaching sessions. This technique encourages participation from peers and the facilitator is often quiet as the 'absent friend' [5]. I felt like this approach was useful in trying to get the students to think about other student's presentations, which encourage reflection.

The feedback for the sessions were extremely positive, I realised that clinical competence is more than just a skill. Even if simulation did not improve the technical ability of students, it would encourage the learners to develop reflective skills, and build confidence for future sessions in the department.

\section{References}

[1] Tan S.S, Sarker S.K. (2011) 'Simulation in surgery: a review', Scottish Medical Journal 56(2), pp. 9. Available from: 10. 1258/smj.2011.011098.

[2] Ali K, A. McCarthy, J. Robbins, E. Heffernan and L. Coombes (2013). 'Management of impacted wisdom teeth: teaching of undergraduate students in UK dental schools'. European Journal of Dental Education ISSN 1396-5883

[3] General Dental Council, (2011). "Preparing for practice-dental team learning outcomes for registration". https://www.gdc-uk.org/professionals/students-and-trainee s/learning-outcomes (15 September 2017).

[4] Exley, K. and Dennick, R.G., (2004) Small Group Teaching: Tutorials, Seminars and Beyond, RoutledgeFalmer, London.

[5] McCorie, P., (2006) Teaching and leading small groups, Association for the Study of Medical Education, Edinburgh.

[6] Colliver, J and Markwell, S., (2007) 'Analysis of methods and findings', Medical Education. 41(1), pp. 533535 .

[7] Bishop JL, Verleger, MA., (2013)' The flipped classroom: A survey of the research', American Society for Engineering Education National Conference Proceedings Atlanta, GA, 30 (9), pp. 1-18.

[8] Johnson, D.W., Johnson, R.T. and Smith, K., (2014), 'Cooperative Learning: Improving University Instruction by Basing Practice on Validated Theory', Journal on Excellence in College Teaching, 25(4), pp. 85-118. 
[9] Kolb, D., (1984) 'Experiential Learning - Experience as the Source of Learning and Development', PrenticeHall, New Jersey.

[10] Race, P., (2015) 'The lecturer's toolkit: a practical guide to assessment, learning and teaching', Routledge, London.

[11] Lave, J. and Wenger, E., (1991) 'Situated learning: Legitimate peripheral participation', University press, Cambridge.

[12] Vygotsky, L., (1978) 'Interaction between learning and development From: Mind and Society', Harvard University Press, MA. pp. 79-91.

[13] Cartwright, S., (2002) 'Double loop learning: A concept and process for leadership educators', Journal of leadership Education, 1(1), pp. 68-71.

[14] Rogers, T., (2014) 'Overcoming implementation challenges with problem and project-based learning in advances technological education programmes within community colleges', Massachusetts, Northeastern University; https://repository.library.northeastern.edu/files/ neu:349670/fulltext.pdf (10 October 2017).

[15] Issenberg SB, Mcgaghie WC, Petrusa ER, Gordon, L and Scalese R., (2005) 'Features and uses of high-fidelity medical simulations that lead to effective learning: a BEME systematic review', Medical Teacher. 27 (1), pp. 10-28. BEME systematic review', Medical Teacher. 27 (1), pp. 10-28.

[16] Zangrando, MS., Ragghianti, Sant'Ana, Adriana CP, Greghi, Sebastião LA., de Rezende, Maria Lucia, R., (2014) 'Pig Mandible as a Valuable Tool to Improve Periodontal Surgery Teachniques', International Education Studies. 7(10), pp. 82-88.

[17] Driessen E, Tartwijk J, Dornan T. (2008) 'The SelfCritical doctor: helping students become more reflective', British Medical Journal, 336 (7648), pp. 827-829.

[18] Schön, D.A., (1987) Educating the reflective practitioner, Jossey-Bass, San Fransisco.

[19] Luhanga, FL, Billay, D, Grundy, Q., (2010) 'The oneto-one relationship: is it really key to an effective preceptorship experience? A review of the literature', International Journal of Nursing Education Scholarship, 7(1), pp. 1-15.

[20] Fugill, M., Teaching and learning in dental student clinical practice. (2005). European Journal of Dental Education, 9(3), pp. 131-136.

[21] Cope, P., Cuthbertson, P., Stoddart, B., (2000) 'Situated learning in the practice placement,' Journal of Advanced Nursing. 31(4), pp. 850-856. 